\title{
Scientists Collaborating with Industry: An Exploration of Industry Engagement Types
}

\author{
Kamrun Nahar Munny ${ }^{1}$, Mostak Ahamed Galib ${ }^{2}$, Ding Lin ${ }^{3}$ \\ ${ }^{1}$ European University of Bangladesh, Bangladesh \\ ${ }^{2}$ School of Marxism, Wuhan University of Technology, Wuhan, China \\ ${ }^{3}$ Wuhan Education Television, Wuhan, China
}

\begin{abstract}
Involvement of researchers in industry is undeniably beneficial for companies. It drives innovations, patents, licenses and ultimately profits. However, participation of scientists in industry is still scarce. With the aim of emphasizing the benefits of scientific involvement in industry, we conducted a comprehensive exploration of various types of involvement. Contributions of scientists to industry sector comes through 5 types of collaboration encompassing: licensing, collaborative research, academic entrepreneurship, contract research and consulting. This kind of typology enables practitioners to see what collaboration type they may engage in and is optimal for their business needs.
\end{abstract}

Keywords: Industry engagement, Licensing, Collaborative research, Academic entrepreneurship, Contract research

\section{Introduction}

The literature on researchers' engagement in industry shows that the engagement choices are governed by a wide variety of factors, including inter-institutional structures (Landry and Amara, 1998); formal (Wen and Kobayashi, 2001) and informal research networks, research alliances and covenants (Pisano, 1991) and arrangements for sharing expensive or scarce scientific resources and equipment (Kevles, 1995). The involvement of researchers with industry requires both desire for involvement and the ability to move beyond the theory and curiosity driven research into practical research application. Generally, the industry is more interested in recruiting researchers to deal with shortterm problems and apply their empirical research that can assist either in solving a problem the companies face or in providing the foundations for commercializable technologies and products. This can be specifically for prolonging the product life cycle (PLC) and for R\&D objectives. Many university have designed policies that aim to promote industry involvement, internships, technology transfer, and commercialization across the whole institution. According to Clark (1995), universities are a collection of discipline-based schools and departments with their own norms and standards for dealing with research and industry linkages rather than concentrating on a single and homogeneous organization. Building positive reputation and prestige of research at the university requires academic disciplines foundations (Knippenberg and Ellemers, 2003) and is profoundly tied to individual departments and programs (Brewer et al., 2002). University departments are operated by the institutional rules, norms and prospects with which individuals are expected to conform (North, 1990). Industry engagement in concerning working on collaborative activities requires academicians to bridge between the academic science and institutional logics of industrial practice (Thornton and Ocasio, 2008). The norms of knowledge production and distribution, career employment patterns and the time scales of research efforts reflects the differences in institutional logics (Sauermann and Stephan, 2013). Strong tendency that academicians have in identifying the institutional logic of science and working with industry partners can present significant challenges for academician in their ways to carry out job related tasks (Lin and Bozeman, 2006). OwenSmith and Powell (2001) adds that academicians have to learn how to furnace relationships with industry that generate 
beneficial outcomes for both parties, a win-win scenario. Finding appropriate partners and sustaining the relationships often requires the academicians to maintain a network of non-academic colleagues (Lam, 2007).

Time and other investments are critical to building reputation outside academia in industry engagement model. Examples of reputation building would be attending meetings with industry partners or taking on roles in the wider profession (D'Este and Perkmann, 2011). The decision to engage with industry for individual researchers depends mainly on their social context and their perceptions of the potential costs and benefits from engagement (Owen-Smith and Powell, 2001; Tartari and Breschi, 2012). In social context perspective, prior research on academic engagement has shown a strong link between industry and leading universities with strong research capabilities. Sufficient institutional support for engagement training, monetary rewards and availability of support with industry may also lead to higher level of academic effort at engagement process (Perkmann et al., 2013). Additionally, academicians' attitudes towards engagement may be motivated and formed by the norms of scientific production and exchange that exist in the main discipline of the academia. However, some disciplines show close attraction to practice and others being distant from industry (Perkmann et al., 2013), yet, (Louis et al., 1989; Stuart and Ding, 2006; Bercovitz and Feldman, 2008; Tartari and Breschi, 2012) supplement the local work context to this attraction and practice of industry engagement scenario. In our study, we build a foundation for research in industry involvement by conducting a review of various types of engagement.

\section{Types of industry engagement}

Researchers and universities as a holistic system engage with industry in a variety of different ways such as; research contracts which is a type of collaboration that occur when the industry approach researchers to find a solution to a problem or to develop new products, processes or services. These can be either short or long-term arrangements and may be funded exclusively by the company or through other sources such as government. In this regard, companies have the opportunity to license any resulting intellectual property (IP). Service or consulting contracts are type of engagement between industry and academia that often involves a faculty member or student carrying out a small consulting project, product testing or lab analysis using company's specialized infrastructure and experienced technical staff. Project turnaround time for these projects is fast and is a great way to experience what the industry has to offer (Tartari and Breschi, 2012). Thirdly, research grants which refers to donations from industry to a faculty researcher or group of researchers to support research of mutual interest. Fourth is the use of facilities - company's state-of-the-art research facilities and equipment - by academia for rent for certain research projects. Fifth is licensing or acquiring technologies from a company for aiding in the development and significant portfolio of products available for companies to access either through an assignment or through license. Sixth, the student projects engagement which involves student-related projects that provide opportunities for undergraduate and graduate students in educational or research projects, cooperative placements or summer employment to engage with the industry.

Table 1. Types of industry engagement

\begin{tabular}{|l|l|}
\hline Licensing & $\begin{array}{l}\text { Contractual assignment of university-generated intellectual property (such as } \\
\text { patents) to external organizations }\end{array}$ \\
\hline Academic entrepreneurship & $\begin{array}{l}\text { Development and commercial exploitation of technologies pursued by } \\
\text { academic inventors through a company they (partly) own }\end{array}$ \\
\hline Collaborative research & $\begin{array}{l}\text { Research jointly pursued by university/PhD researchers with industrial } \\
\text { partners- commonly with public funding. }\end{array}$ \\
\hline Contract research & $\begin{array}{l}\text { Application-oriented research and development activities carried out by } \\
\text { academicians/PhD researchers- commissioned and funded by industry. }\end{array}$ \\
\hline Consulting & $\begin{array}{l}\text { Application-oriented research and development activities or advice provided } \\
\text { individually by academicians- commissioned and funded by industry. }\end{array}$ \\
\hline
\end{tabular}

Sources: Bercovitz and Feldman (2006); Mansfield (1995); Louis et al (1989).

Lastly, other partnerships of academia with industry partners on a wide variety of initiatives, both within the university and in partnership with other organizations. Relational types of involvement, such as collaborative research, contract research and consulting are more widespread and seen as more relevant by firms (D’Este and Patel, 2007; Cohen et al., 
2002). The insights from patenting and academic entrepreneurship, therefore, cannot easily be generalized. Actual relational involvement with industry may demand more faculty time and dedication than patenting, which may be a byproduct of the research. Furthermore, collaboration differs from academic entrepreneurship in a sense that it tends to be informed by research-related rationales rather than an explicit desire to appropriate the financial returns on academic knowledge (D'Este and Perkmann, 2011). This means collaboration may be more strongly driven by complementarities, achieved by working with industrial partners and pursuing academic research, rather than a single-minded focus on commercial success (Owen-Smith, 2003).

\subsection{Licensing and academic entrepreneurship}

Licensing and academic entrepreneurship are only moderately important means through which industry appropriates university-generated knowledge (Arundel and Geuna, 2004; Perkmann and Walsh, 2007; Faulkner and Senker, 1994; D'Este and Patel, 2007). Drawing on survey evidence from literature relating to different industry engagement types, we found that US research and development (R\&D) executives place the highest value on contract research, followed by co-operative research, licensing judged as less relevant (Roessner, 1993). According to the Carnegie Mellon Survey on industrial R\&D, US R\&D executives regard consulting; they argue that contract research and joint research as more relevant channels than licensing (Cohen et al., 2002). A number of various studies (Levin et al., 1987; Klevorick et al., 1995; Mansfield, 1991; Pavitt, 1997; Agrawal and Henderson, 2002; Schartinger et al., 2002; D’Este and Patel, 2007) found similar results pointing to the relatively low importance of intellectual property (IP) transfer. In this study, we focus on these relational forms of engagement. For brevity, the term "industry engagement" in this study is focused on the motives of researchers toward collaborative research, contract research and consulting.

\subsection{Collaborative research}

Hall et al., (2001) defines collaborative (or joint) research as a formal collaborative arrangements aimed at cooperation on R\&D projects. In many cases, the projects of this kind are often subsidized by public funding. Interdisciplinary teams are increasingly enacting the work within contemporary organizations (Blackler and Regan, 2009, Czarniawska, 2004, Lindkvist, 2005; Nicolini et al., 2012). This is because collaboration at this level is across knowledge domains which is recognized as a source of competitive advantage not just for the company but also for the university (Liedtka, 1999 and Scarbrough and Swan, 2008) and as a response to the complex demands that the modern world face (Aram, 2004, Buanes and Jentoft, 2009, Huutoniemi et al., 2010, König et al., 2013 and Van Rijnsoever and Hessels, 2011).

\subsubsection{Contract research}

Contract research refers to research that is commercially relevant directly to firms and, therefore, is commonly ineligible for public support. Firms explicitly commission the contract research and the work is usually more applied than in collaborative research arrangements (Van Looy et al., 2006). Finally, consulting is the research or advisory services that individual or academic researchers provide to their industry clients (Perkmann and Walsh, 2008). Contract practices of research suggests that novel types of collaborations exist between industry and contract researchers. These models at times imprecise the differences between biotech companies and fee-for-service clinical trial operations. A study by Sariola et al., (2015) found links contract research and the industry

1) Outsourcing - Larger companies sometimes a university join up with a contract research organization. Larger companies usually develop the experimental compound that could be regional or national players. However, some companies have their own operational space, but most of them are lean which means they just handle parts of the process, such as regulatory, reporting or data management and outsource the rest of the operations.

2) Small tie-ups - Smaller companies which can consist of 1-2 scientific personnel can outsource the complete product development to contract researchers. Bigger to medium size that can consist of more than 12 people in single company can handle some parts of the development process themselves. Still they probably outsource different parts of the process to different bodies.

3) Preferred partnerships - are companies that prefer to work with the research partner that can give them an opportunity to carryout full service and outsource only small part of their services. 
4) Sub-contracting model - refers to companies that outsource all the work or certain parts of the development process, for instance, a particular lab test. This is commonly one-off relationship, which involves only irregular contact, with no formal relationship.

\subsection{Consulting}

Projects that are consultancy based are typically commissioned directly by the industry partner and the income consequent from them often accumulates to individuals although it can be channeled through university research accounts to support research undertakings. Studies of academic consulting are hindered by the fact that many consulting activities go unreported (Thursby et al., 2009; Abramovsky et al., 2007). However, a number of prior studies on both quantitative and qualitative approaches suggest that consulting is a widespread practice among academic researchers with most authors finding a positive relationship between qualities of faculty and consulting engagement (Boyer and Lewis, 1984; Louis et al., 1989; Agrawal and Henderson, 2002). Projects based consultancy between researchers and industry happens in the following forms;

\section{(a) Opportunity-driven consulting}

Consultancy type in which academicians engage in consulting motivated by personal income opportunities. Such income-oriented view is predominant in literature as an engagement motivator (Boyer and Lewis, 1984). It is also implicit in life cycle theories predicting that junior researchers focus on building an academic career while they capitalize on their expertise by engaging with industry later on (Stephan and Levin, 1992). For academicians, the marginal cost associated with providing consulting is relatively low because they possess the required expertise, letting them to appropriate rents. Academicians are known as specialists in certain areas of expertise and, therefore, firms engage them to resolve specific problems within the industry (Gibbons and Johnston, 1974). In this view, consulting diverges from other university-industry relationships in that it organizes expertise that is commonly held within academia (Agrawal and Henderson, 2002). Rather than commercializing the newest discoveries, the relationship leverages old science (Rosenberg, 1994). Consulting of such nature resolves on problems and provides enhancements that are not only suggesting new project ideas or pioneering new design configurations (Cohen et al., 2002). In order to attain this, researchers will not need prior knowledge about the client organization and its technology, and in terms of the relationship, assignments might, therefore, be short-term and time-bound.

Opportunity-driven consulting is usually seen to be of lesser academic value and is not necessarily complementary with academic research (Boyer and Lewis, 1984), as it does not directly contribute to research or teaching. A survey conducted in the UK by Howells et al., (1998) suggests that the barriers for academicians to engage in consulting are to some extent different from those for collaborative research. A study by Howells et al., (1998) found that the consultancy work was "not interesting" for researchers, and lack of career impact was also found among the barriers to consulting activities, indicating that academicians perceive a trade-off between consulting and their primary interests. Opportunity-driven consulting follows a different logic. The role of opportunity-driven research it may be used by a broader range of firms and may be overlooked by studies focusing on large R\&D-active firms. Demand for opportunity-driven academic consulting is likely to exist particularly within smaller firms. Large firms with differentiated R\&D, design or production engineering departments have less need for the type of problem solving capability and issue-centered advice implicit in opportunity-driven consulting. In smaller firms, innovation is often more informal and relying on external sources due to the fixed costs involved in maintaining specialist expertise and equipment. However, for many smaller firms, the main sources of innovation are either internal or within their vertical supply chains (Mansfield, 1991). For instance, both specialized supplier and supplier-dominated firms rely on their vertical value chains for their innovative inputs (Pavitt, 1984) and are hence less likely to use academicians as external collaborators. By contrast, new technology based firms (NTBFs) focus on specific proprietary technologies as the basis for their products and services (Bollinger et al., 1983). NTBFs are the most likely clients for opportunity-based consulting activities as their focus is primarily on development rather than basic R\&D. However, Kciopar (2010) focused on the three main factors that build engagement, namely dedicated research center, project based research, and fixed hours. 


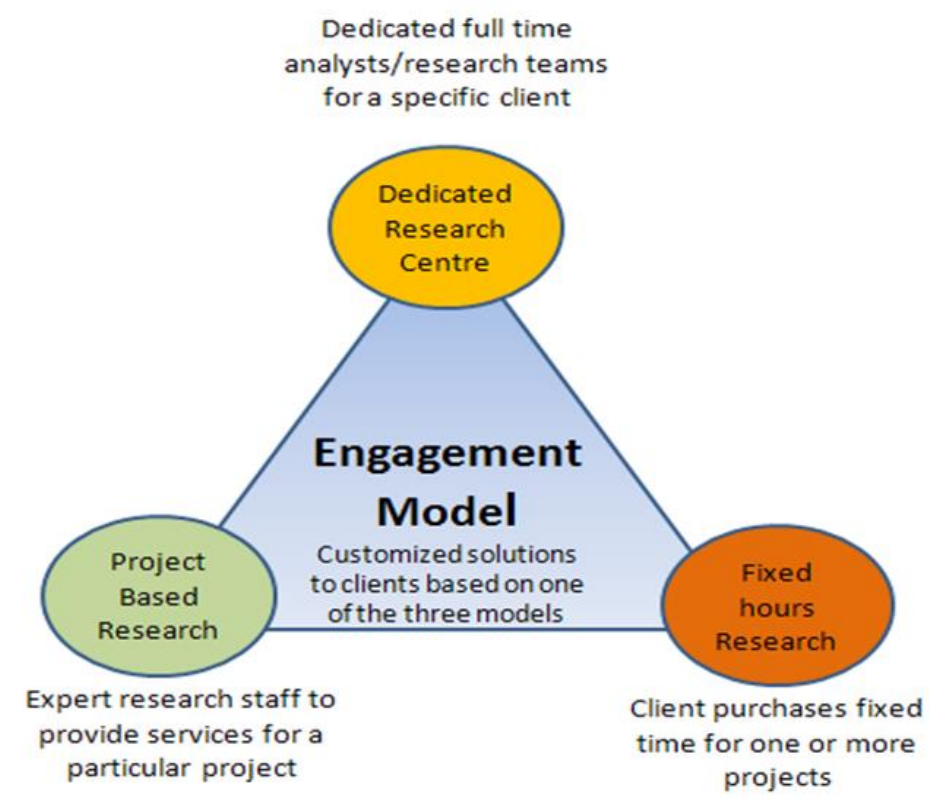

Figure 1. Engagement model triangle (source: Kciopar, 2010)

Such firms, that tend to be start-ups in sectors such as electronics, instruments, biotechnology and software, may resort to hiring academicians for problem-solving and testing concepts. Yet some dissonant evidence suggests that opportunity-driven consulting is not the only logic inherent in academic consulting. A study conducted in Belgian indicate that researchers involved in contract research generally published more than their pure academic colleagues while their research activities were not visibly skewed towards more applied themes (Van Looy et al., 2004). According to the studies done by Boyer and Lewis, (1984); Patton and Marver, (1979) found that academicians' decisions to engage in consulting were not primarily driven by financial motives and that consulting academicians are at least as academically active as their non-consulting peers (. Below, we therefore consider two alternative views on consulting.

\section{(b) Commercialization-driven consulting}

Consulting can also be linked to academicians' efforts to commercialize their own technologies (Agrawal, 2006; Shane, 2004). Hiring inventors as consultants constitutes an obvious option for a licensee to access their expertise. Inventor involvement is critical for the commercial success of university-generated technologies that are often embryonic. According to a US survey, $71 \%$ of out licensed inventions including to spin-offs required inventor assistance for being successfully commercialized (Thursby et al., 2001). Inventors commonly retain their faculty position and work with the commercializing entity via consulting, contract research, personnel exchange and advisory board presence (Goldfarb and Henrekson, 2003). In addition to spin-off companies, large existing firms licensing university technology also benefit from inventor collaboration. A US study showed that approximately $40 \%$ of university licensees indicated that the technologies could not be successfully commercialized without faculty co-operation (Thursby et al., 2004). Agrawal (2006) found that for two-thirds of a sample of MIT-owned licenses, academic inventors were involved in the further development of the technology. Consulting motivated by commercialization strategies differs from opportunitydriven consulting in several respects. Inventions will usually be the output of academic research, possibly pursued over long periods. Motivationally, therefore academicians will be driven more intrinsically by the desire to see their inventions flourish as an extension of their research. Secondly, the relationship between academicians and clients is likely to be a stable arrangement, possibly comprising financial ties (Boyd and Bero, 2000). The remit of the relationship focuses on a specific project, implying that the academic might have a position a kin to an external member of a development team who can be called upon when needed. To answer the question of why do firms engage academicians as consultants? The answer is most obvious for commercialization-driven consulting provided by academic inventors to the licensees of university-generated technology. As information contained in patents is often insufficient for successfully exploiting technology, particularly in novel industries, valuable expertise tends to be tacit and complex, and hence naturally exclusive (Zucker et al., 2002). Although the underlying knowledge might not by definition be un-modifiable, it might be too costly to do so against its perceived value, meaning that it remains latent (Agrawal, 2006). Personal involvement via commercialization-driven consulting represents a mechanism for firms to 
capture such latent knowledge (Zucker et al., 2002). This enables firms to enjoy first-mover advantages before the expertise diffuses via codification. Given the self-interest of the academic consultants in 'their' technology they are unlikely to be disinterested judges of the risk associated with a chosen path. Partly because of 'moral hazard' on the part of the inventor (Jensen and Thursby, 2001), commercialization-driven consulting is unlikely to be of strategic, path-selecting nature.

\section{(c) Research-driven consulting}

In a third scenario, consulting activities are directly linked to academicians' research projects. Academicians often maintain consulting relationships with firms that support their research. Mansfield (1995) reported that in all industries in exception of pharmaceuticals, over half of a sample of highly industry relevant academicians were indicated that the problems and ideas they worked on in their government-funded research often developed out of consulting. Murray's (2002) work on tissue engineering also points to a distinctive research-driven logic. (Agrawal and Henderson, 2002; Gittelman and Kogut, 2003), that there is limited network involvement overlay between paper authoring academicians and patent-authoring researchers, suggesting that inventors are different from researchers. The academicians however, engage with the industry in various ways, including consulting, advisory board membership and sponsored research (Murray, 2002). Similarly, consulting was found to be a significant predictor of all other forms of academic entrepreneurship (Louis et al., 1989). Rather than opportunity-driven income seeking, such consulting is motivated by the desire to gain insights into industry challenges or access to research materials. Cohen et al. (2002) found that firms use academic consulting often in unification with other open science mechanisms, for instance, joint research, informal interaction and conferences. This result suggests that such consulting activities are research driven, in agreement with 'Mertonian' objectives (Merton, 1973).

The ensuing relationships will be strongly socially embedded and characterized by ongoing barter-like interactions (Kreiner and Schultz, 1993). Consequently, while formal consulting assignments in this context are remunerated, some irregular and informal advice may be provided in an untraded manner (Faulkner and Senker, 1994). In terms of the knowledge mediated in this type of relationship, one can expect a strong prominence on interactive learning and knowledge co-production (Rosenberg, 1994). Research-driven consulting signifies one of the channels through which techniques and instrumentation are developed via mutual interaction between industry and academia (Rosenberg, 1992). Equally, the deep understanding of a firm's technology trajectory built through continuous interaction enables academicians to provide advice on strategic R\&D decisions. Some researchers have 'scientific taste', allowing them to evaluate the likely payoff of different lines of research and advise firms regarding their relative merits (Zucker et al., 1998). By contrast, research-driven consulting is attractive to firms that regularly engage with university academicians, for instance in aerospace and pharmaceuticals (Cohen et al., 2002) and commonly in high-technology industries. Amongst these, particularly the larger companies with formal research and development operations have the required absorptive capacity (Cohen and Levinthal, 1990). The basis for accessing university-based research for these companies is to extend in-house basic research and provide strategic windows on emerging technologies (Santoro and Chakrabarti, 2002). Such companies often pursue innovation strategies with high degrees of complexity and uncertainty (Tidd, 2001). The use of external academic expert judgment within such selection processes represents one of the mechanisms to reduce uncertainty (Pavitt, 2005). Researchers therefore play a role, comparable to entrepreneurship, as 'knowledge filter' (Santoro and Chakrabarti, 2002), bridging the link between knowledge creation and its purposeful exploitation.

Table 2. Summary of consulting types

\begin{tabular}{llll}
\hline & Motive & Relationship & Type of knowledge \\
\hline Opportunity-driven & Income & Short-term & Openly accessible, specialist expertise \\
Commercialization-driven & Technology development & Project-bound & Tacit expertise \\
Research-driven & Research opportunities & Long-term, embedded & Strategic judgment, know-what \\
\hline
\end{tabular}

\section{PhD researchers' impact on $R \& D$}

Beltramo et al. (2001), by means of interviews carried out in firms localized in France, Spain and the United Kingdom, analyzed aspects more concerned with firm strategy, arriving to the conclusion that the R\&D organization and a firm's tendency to reach external $\mathrm{R} \& \mathrm{D}$ agreements had a positive influence on $\mathrm{PhD}$ recruitment. Thus far, scientists have a 
significant impact toward R\&D of industries. Garcia-Quevedo, Mas-Verdu, and Polo-Otero (2012) and Herrera, Felisa Munoz-Doyague, and Nieto (2010) have analyzed the factors influencing the recruitment of scientists empirically. The former study analyzed the mobility of researchers from public R\&D centres to firms, found that large firms in the high and medium technology sectors, with a high level of formalization of R\&D activities had a greater tendency to recruit researchers. The latter study is perhaps the only research so far to have analyzed the factors determining the recruitment of PhDs, concluding that the intensity of R\&D activities, employing PhDs for research and development reasons in the past and the university-firm relationships all had a positive and significant influence.

In addition, we have also identified an integrative role that the literature has linked to the well-known absorptive capacity concept (Cohen and Levinthal, 1990). PhD holders can allow firms to systematically test and evaluate the latest extra-mural research with respect to their technological strategy (Song et al., 2003). Some authors specifically call these roles gate keeping and boundary spanning roles, which facilitate firms to develop abilities with regard to collecting, assimilating and applying external knowledge (Rothaermel and Hess, 2007). Owing to their exposure to the academic and to the commercial worlds, $\mathrm{PhD}$ holders can entail for firms a substantial advantage to accurately assess the implications of the current research from a commercial point of view (Zellner, 2003). According to Hess and Rothaermel (2011, p. 987) a scenario without scientists acting as translators implies that "the firm would potentially be unable to assimilate tacit information into codified knowledge that can lead to future innovation".

$\mathrm{PhD}$ holders also play connective roles, which allow firms to access networks and communities of scientific knowledge. The literature states that $\mathrm{PhD}$ researchers develop social capital during their research careers through their interaction with regard to different social and professional contexts (Dietz and Bozeman, 2005). This social capital may be used to bring firms closer to scientific knowledge networks allowing them to form alliances with other researchers, universities or technological centres. The recruitment of $\mathrm{PhDs}$ in this field may help to overcome difficulties to find innovation partners (Hess and Rothaermel, 2011). Firms can seek cooperation with other agents through their scientists to fill in a particular knowledge gap during the innovation process or to gain legitimacy among the scientific community (Almeida, Hohberger, and Parada, 2011). Almeida et al. (2011) and Murray (2004) have even gone further, stating that this social capital might have major repercussions on the firm's innovation output.

\section{Discussion and implications}

The significance of highly qualified human capital in relation to firms' innovation activities has been analyzed by different researchers who have recognized that knowledge is the most important competitive resource that a firm holds residing in its human capital (Lepak and Snell, 1999; Levinthal and March, 1993; March, 1991). This literature has concentrated on alumni with miscellaneous qualifications and has followed related arguments with regard to the role of highly skilled employees in the development of the innovation process, prior studies having agreed that they create ideas that set the innovation process into motion and monitor the external environment to take advantage of the knowledge generated outside of the firm for internal innovation acceleration (Chen and Huang, 2009; Laursen, 2002; Shipton, West, Dawson, Birdi, and Patterson, 2006). In this context, the employment of PhD researchers has become an imperative object of analysis, as PhDs are trained to undertake research, possess the highest educational level and are therefore considered the highest qualified work force for the implementation and diffusion of knowledge and innovation (Auriol, 2010).

Notwithstanding the prominence given to researchers in firms, a major limitation of investigations which analyze their movement consists of a disproportion between the studies concerning the supply side (individual level) and the demand side (firm level). Review of literature on this topic has primarily focused on analyzing the individual factors which foresee the preferences for research careers carried out in the industry other than academia, studies having shown that those researchers interested in a good financial compensation and in downstream research are more likely to prefer careers in established firms (Roach and Sauermann, 2010) while the quality of the research was found not a significant criterion in seeking a permanent position in the industry (Mangematin, 2001). PhDs develop a range of skills during their doctoral studies and their scientific careers, which could be useful to firms at different stages of the innovation process. By using an upstream- downstream approach to understand the role of $\mathrm{PhD}$ researchers taking part in this process, Hess and Rothaermel (2011) stated that the traditional upstream-downstream approach that has been applied to comprehend the strategic alliances can further be useful to better comprehend the role played by the intellectual capital in firms, because this classification reflects the knowledge which is needed to expedite the innovation at different points along of the value chain. For the reason that the literature analyzing the role of researchers lacks any 
clear-cut conceptualization of the upstream and downstream activities (Beltramo et al., 2001), it is imperative to link upstream research activities to the generation and absorption of the knowledge processes (exploration) while the downstream research activities are related to production and marketing (exploitation). Due to the fact that firms undertake different R\&D projects, it is normal to find firms involved simultaneously in these two types of activities. A short review of the literature was undertaken by D'Este et al. (2014) suggesting that these activities may complement each other and that firms develop ambidextrous capabilities when simultaneously undertaking exploration and exploitation activities which could allow them to achieve a better economic performance.Extant research has clearly established that the role of scientists in firms is especially justified during the early stages of the innovation process as they can bring into the company not only the most up-to-date knowledge but in addition also the skills needed to produce and absorb it (Lee, Miozzo, and Laredo, 2010). Based on the literature we can assume that, in general, upstream research activities of the innovation process are often seen as the natural field of work for PhD holders in firms. We have at least identified three roles which $\mathrm{PhDs}$ could play throughout these activities. The first one consists in a knowledge provider role which is deeply rooted within the intellectual capital that $\mathrm{PhD}$ holders contribute to firms and which is derived from their advanced education, training and experience in undertaking scientific and technological research (Luo, Koput, and Powell, 2009; Subramaniam and Youndt, 2005). This intellectual capital is especially valuable given that firms could gain a competitive advantage from the knowledge embodied by their PhDs, which other firms would not be able to imitate. In addition, it has also been shown that when this knowledge is technologically distant from the firm's knowledge base the recruitment results in a significant technological reposition of the firm (Tzabbar, 2009) allowing to extend the technological boundaries of firms (Song, Almeida, and Wu, 2003). An additional finding involves the attraction felt by scientists towards the private sector as being related to the investigator's perception of the commercial potential of their research (Fritsch and Krabel, 2012). In this line, Zucker, Darby, and Armstrong (2002a) found that top academic scientists moved more readily from academia to the private sector if they had a high-level intellectual capital relevant to the commercialization of inventions. It has therefore been found that scientists with patenting and narrower technological experience value more highly working in firms than those without patents (Fritsch and Krabel, 2012). At a firm level, so far few studies have analyzed the demand for PhDs by firms and those that exist have analyzed experience in certain specific sectors, mainly in the high technology areas (Zucker et al., 1998a, 2002a; Zucker, Darby, and Torero, 2002b). Conclusions drawn highlight that high-tech firms with a high dependency on scientific knowledge and some absorptive capacity are more likely to hire PhDs (Auriol, 2010; Cruz-Castro and Sanz-Menéndez, 2005).

Studies have also shown than in certain disciplines such as biology, PhDs pay a compensating differential to stay in science, accepting lower wages to continue undertaking research (Stern, 2004) and that their alma mater plays a determining role at the moment of collaborating with the industry to reduce the labour market uncertainties (LancianoMorandat and Nohara, 2006). Other significant contextual determinants include the fact that PhDs hired by firms are unlikely to remain in the cities where they studied (Stephan, 2006), as is a well-established fact that some regions attract more PhDs than others, especially those with more R\&D expenditure and research infrastructures (Sumell, Stephan, and Adams, 2009). The need to facilitate the development of collaborative practices among academicians and industry is important toward the end benefits of industry engagement. There have been increasing organizational pressures to support the development of more collaboration between disciplines and professions (Adler and Heckscher, 2006, Adler et al., 2008 and Lyall and Meagher, 2012), and in particular an increasing number of initiatives to promote the development of engagement between academicians and industry (Khapova and Arthur, 2011). Despite the recognition that individual scientists contribute to industries might depend on development of new skills in university (Lattuca, 2002) and the emergence of new practices, perceptions and attitudes towards industry engagement. (Nooteboom, 2008, Olsen, 2009, Scarbrough and Swan, 2008 and Siedlok and Hibbert, 2014), practitioners and researchers often remain over-focused on the structural aspects of such collaborations. These include, for example, the physical aspects of the engagement network (Gherardi, 2009a), resulting in new organizational arrangements, policies and funding (Stokols et al., 2012). Indeed, imposing a certain organizational form is often assumed to be the most important factor for enabling the facilitation and cultivation of engagement (Cox, 2005, Kirkman et al., 2013, Thompson and Walshmam, 2009 and Wenger et al., 2002).

\section{Conclusion}

University bound research contribute positively to a firm's innovative capacity by providing access to know-how and facilities. These are critical in advancing expertise and technologies leading to tangible economic outcomes like patents, 
licenses, non-patented and non-licensed new products and processes (Santoro and Betts, 2002; Santoro and Chakrabarti, 2001). Thus, the increase of speed for new product to market is attained (Mowery, 1998) and escalate a firm's market share (George et al., 2002). Given the value of engaging scientists into industry, future studies should focus on how to increase the number of them working with industry.

\section{References}

- Agrawal, A., 2006. Engaging the inventor: Exploring licensing strategies for university inventions and the role of latent knowledge. Strategic ManagementJournal 27 (1), 63-79.

- Agrawal, A., Henderson, R. M., 2002. Putting patents in context: Exploring knowledge transfer from MIT. Management Science 48 (1), 44.

- Boyer, E. L. 1996. The scholarship of engagement. Journal of Public Service and Outreach, 1 (1), 11-20.

- Buanes, A., \& Jentoft, S. (2009). Building bridges: Institutional perspectives on interdisciplinarity. Futures, 41(7), 446-454..

- Cockburn, I. M., Henderson, R. M., 1998. Absorptive capacity, coauthoring behavior, and the organization of research in drug discovery. Journal of Industrial Economics 46 (2), 157-182.

- Cohen, W. M., Nelson, R. R., Walsh, J. P., 2002. Links and impacts: the influence of public research on industrial R\&D. Management Science 48 (1), 1-23.

- Czarniawska, B. (2004). On time, space, and action nets. Organization, 11(6), 773-791.

- D'Este, P., Patel, P., 2005. University-industry linkages in the UK: what are the factors determining the variety of university researchers' interactions with industry? Paper presented at the DRUID conference, Copenhagen June 27-29.

- Faulkner, W., Senker, J., 1994. Making sense of diversity: public-private sector research linkage in three technologies. Research Policy 23 (6), 673-695.

- Gibbons, M., and Johnston, R. 1974. The roles of science in technological innovation. Research Policy (3:3), pp. 220-242.

- Geuna, A., \& Muscio, A. (2009). The governance of university knowledge transfer: A critical review of the literature. Minerva, 47(1), 93-114.

- Henderson, R., 1994. The evolution of integrative capability: innovation in cardiovascular drug discovery. Industrial and Corporate Change 3 (3), 607-630.

- Henderson, R., Cockburn, I., 1994. Measuring competence-exploring firm effects in pharmaceutical research. Strategic Management Journal 15, 63-84.

- Henderson, R., Jaffe, A. B., Trajtenberg, M., 1998. Universities as a source of commercial technology: a detailed analysis of university patenting 1965-1988. The Review of Economics and Statistics 80 (1), 119-127.

- Kevles, D. J. (1995). The physicists: The history of a scientific community in modern America. Harvard University Press.

- Lam, A. (2007). Knowledge networks and careers: Academic scientists in industry-university links*. Journal of management studies, 44(6), 993-1016.

- Liedtka, J. (1999). Linking competitive advantage with communities of practice. Journal of Management Inquiry, 8(1), 5-16.

- Lindkvist, L. (2005). Knowledge Communities and Knowledge Collectivities: A Typology of Knowledge Work in Groups*. Journal of Management Studies, 42(6), 1189-1210.

- Mansfield, E. (1991). Academic research and industrial innovation. Research Policy, 20(1), 1-

- Mansfield, E. (1995). Academic research underlying industrial innovations: Sources, characteristics, andfinancing. Review of Economics and Statistics, 77(1), 55-65.

- Mansfield, E., 1995. Academic research underlying industrial innovations: sources, 23 characteristics, and financing. The Review of Economics and Statistics 77 (1), 5565.

- Merton, R. K. (1973). The sociology of science. Theoretical and empirical investigations. Chicago, London:University of Chicago Press.

- Merton, R. K., 1973. The sociology of science. Theoretical and empirical investigations. University of Chicago Press, Chicago, London. 
- Merton, R.K., 1973. The Sociology of Science: Theoretical and Empirical Investigations. University of Chicago Press, Chicago.

- .

- Murray, F., 2002. Innovation as co-evolution of scientific and technological networks: Exploring tissue engineering. Research Policy 31 (8,9), 1389.

- Murray, F., Stern, S., 2007. Do formal intellectual property rights hinder the free flow of scientific knowledge? Journal of Economic Behavior and Organization 63 (4), 648-687.

- Owen-Smith, J., Powell, W.W., 2001. Careers and contradictions: faculty responses to the transformation of knowledge and its uses in the life sciences. Research in the Sociology of Work 10, 109-140.

- Owen-Smith, J., Powell, W.W., 2004. Knowledge networks as channels and conduits: the effects of spillovers in the Boston Biotechnology Community. Organization Science 15 (1), 5-21.

- Patel, P., \& Pavitt, K. (1997). The technological competencies of the world's largest firms: complex and pathdependent, but not much variety. Research policy, 26(2), 141-156.

- Pavitt, K. (1984). Sectoral patterns of technical change: towards a taxonomy and a theory. Research policy, 13(6), 343-373.

- Perkmann, M., and Walsh, K. 2009. The two faces of collaboration. Impacts of university-industry relations on public research. Industrialand Corporate Change (18:6), pp. 1033-1065.

- Perkmann, M., Walsh, K., 2006. Forms and impacts of academic consulting: a theoretical framework. London, Advanced Institute of Management Research.

- Perkmann, M., Walsh, K., 2007. Relationship-based university-industry links and open innovation: towards a research agenda. International Journal of Management Reviews (forthcoming).

- Pisano, G. P. (1991). The governance of innovation: vertical integration and collaborative arrangements in the biotechnology industry. Research Policy, 20(3), 237-249.

- Rosenberg, N., 1985. The commercial exploitation of science by American Industry. In: Clark, K.B., Hayes, R.H., Lorenz, C. (Eds.), The Uneasy Alliance: Managing the Productivity-Technology Dilemma. Harvard Business School Press, Boston, MA.

- $\quad$ Rosenberg, N., 1992. Scientific instrumentation and university research. ResearchPolicy 21 (4), 381-390.

- $\quad$ Tidd, J., Pavitt, K., \& Bessant, J. (2001). Managing innovation (Vol. 3). Chichester: Wiley.

- van Rijnsoever, F. J., \& Hessels, L. K. (2011). Factors associated with disciplinary and interdisciplinary research collaboration. Research Policy, 40(3), 463-472.

- Zuckerman, H., Merton, R. K., 1972. Age, aging, and age structure in science, in:Riley, M. W., Johnson, M., Foner, A. (Eds.), A Sociology of Age Stratification, New York: Russell Sage Foundation, New York, Russell Sage Foundation, pp. 292-356. 